\title{
Optimalisasi dan Perancangan Algoritma Pergerakan dan Komunikasi pada Robot Penyerang Humanoid Soccer
}

\author{
Daniel Santoso ${ }^{1}$, Deddy Susiloº ${ }^{2}$ Bob William Chandra ${ }^{3}$ \\ Program Studi Teknik Elektro, \\ Fakultas Teknik Elektronika dan Komputer, \\ Universitas Kristen Satya Wacana, Salatiga \\ 12daniel.santoso@staff.uksw.edu, ${ }^{2}$ deddy.susilo@staff.uksw.edu, \\ 3612010003@student.uksw.edu
}

\begin{abstract}
Ringkasan
Robotic Research Centre (R2C) Universitas Kristen Satya Wacana (UKSW) secara rutin mengikuti Kontes Robot Sepakbola Indonesia (KRSBI). Jenis robot yang digunakan adalah humanoid dengan 18 derajat kebebasan dan memiliki kamera sebagai sensor visual. Pengembangan berkelanjutan yang dilakukan oleh R2C telah dapat mengantarkan tim robot sepakbola ini menjadi juara II tingkat nasional pada tahun 2013, meskipun demikian masih ada beberapa masalah mengenai kelincahan manuver dan komunikasi antar - robot. Oleh karena itu pada penelitian ini dilakukukan optimalisasi pada algoritma tracking analisis dan posisi bola, mendekati bola, penentuan orientasi robot, penentuan posisi gawang, menempatkan diri menendang bola, menendang bola, dan komunikasi robot. Pengujian menunjukkan bahwa usaha ini telah dapat meningkatkan respon robot terhadap perpindahan bola, meningkatkan kecepatan dan akurasi dalam mencetak gol, dan membuat robot - robot dalam satu tim dapat berkoordinasi dalam mengejar bola di lapangan.
\end{abstract}

Kata kunci: robot sepakbola, optimalisasi, algoritma, komunikasi

\section{Pendahuluan}

Robotic Research Centre (R2C) Universitas Kristen Satya Wacana (UKSW) setiap tahunnya mengirimkan tim untuk mengikuti Kontes Robot Sepak Bola Indonesia (KRSBI). Robot - robot yang digunakan dalam kontes ini berbentuk menyerupai manusia (humanoid) dan juga bergerak seperti manusia. Robot ini menggunakan kamera sebagai sensor penglihatan dan memiliki 18 derajat kebebasan bergerak.

Seperti layaknya tim sepakbola, robot yang dipakai jumlahnya lebih satu dengan perannya masing - masing. Pada tahun - tahun awal kompetisi, konfigurasi tim KRSBI UKSW hanya terdiri dari satu penyerang dan satu kiper. Seiring dengan perubahan peraturan pertandingan, robot yang digunakan sebagai pernyerang berjumlah lebih dari satu sehingga dibutuhkan komunikasi antar robot agar tidak saling mengganggu ketika robot - robot tersebut sedang mengejar, menggiring ataupun menggiring bola di lapangan. 


\section{Kajian Permasalahan}

Selain masalah koordinasi antar robot, secara individual robot - robot yang dipakai R2C untuk kontes sepak bola masih memiliki beberapa permasalahan yang perlu dibenahi karena akan mengganggu kinerja tim secara keseluruhan. Ringkasan permasalahan tersebut dapat dilihat pada daftar berikut.

1. Pemanggilan motion/gerakan robot belum realtime dan optimal. Robot belum mampu merespon pergerakan bola dengan jeda waktu maksimal 1 detik dan sering terjadi pergantian motion yg tidak diperlukan. Hal ini mengakibatkan waktu yang dibutuhkan robot untuk menghampiri dan menendang bola menjadi lebih lama.

2. Perubahan sudut servo pan (geleng) dan tilt (angguk) kepala tidak sesuai dengan ukuran sudut yang sebenarnya (sudut kompas) dengan resolusi $10^{\circ}$.

3. Ketika robot memutari bola untuk berganti arah, pergerakan robot sering kelebihan memutar dan masih sering menyampar bola sehingga membuat posisi bola jauh dari robot oleh karena robot harus mendekatinya kembali.

4. Proses mengarahkan bola ke gawang lawan membutuhkan waktu lama karena robot harus mengarahkan diri lurus ke daerah lawan baru mengarahkan diri kembali ke gawang lawan. Selain itu tingkat keberhasilan robot dalam mencetak gol masih kurang dari $60 \%$.

Berdasarkan permasalahan di atas, pada penelitian ini dibuat sebuah algoritma untuk mengoptimalkan pergerakan robot dan mengimplementasikan skema komunikasi pada robot - robot penyerang. Diharapkan kedua robot penyerang R2C dapat bermain bola dengan terkoordinasi dan lebih efektif dalam mencetak gol.

\section{Perancangan dan Penerapan}

Sebagaimana umumnya sebuah robot, sistemnya akan terdiri dari mekanik, perangkat keras dan perangkat lunak. Titik berat penelitian ini pada pengembangan dan evaluasi kinerja algoritma pergerakan dan koordinasi robot. Meskipun demikian hal gambaran sistem tetap akan dibahas secara ringkas untuk memberikan pemahaman yang lebih utuh dan sistematis.

Selain kemampuan dasar untuk berjalan dan mengendalikan kestabilan, salah satu kemampuan dasar lain yang harus dimiliki oleh robot humanoid soccer adalah kemampuan mengambil keputusan sebagai pemain untuk melakukan serangkaian pergerakan terbaik dalam berbagai kondisi agar mencapai tujuan [1].

\subsection{Gambaran Sistem}

Sistem instruksi pergerakan pada robot dibagi menjadi 3 bagian utama, yaitu smartphone berbasis Android sebagai prosesor utama yang menentukan gerakan robot yang akan dilakukan, mikrokontroler ATmega324 sebagai kontrol utama yang mengatur kesinambungan antara prosesor utama dengan pengendali motor servo robot Kondo KHR-3HV (RCB-4) dan pemroses data komunikasi yang menggunakan mikrokontroler ATmega8 dengan modul bluetooth sebagai media komunikasinya. Berikut adalah diagram blok dari sistem keseluruhan. 


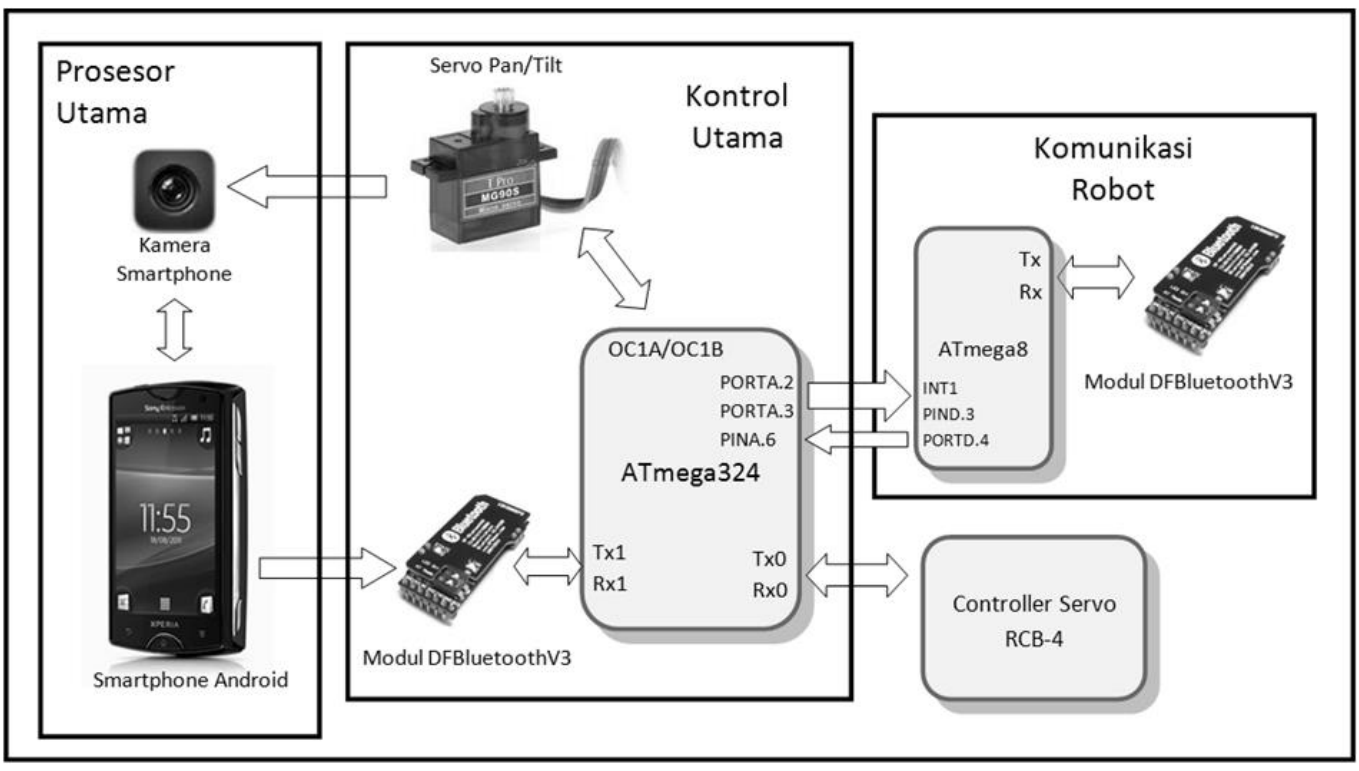

Gambar 1. Diagram blok sistem secara keseluruhan

Prosesor Utama yang digunakan dalam robot adalah sebuah smartphone berbasis Android dengan kamera yang dilepas dan diletakan pada servo pan - tilt. Dalam smartphone ini algoritma pergerakan robot ditanamkan. Tugas utama dari perangkat ini memproses gambar kamera yang diletakan di kepala robot sebagai mata dan mengunci bola [2]. Berdasarkan posisi bola terhadap robot, prosesor utama mengirimkan paket paket data ke kontrol utama melalui koneksi bluetooth.

Kontrol utama robot menggunakan mikrokontroler ATmega324 yang bertugas mengolah paket - paket dari smartphone melalui komunikasi. Ada 3 macam perintah yang dikirim dari smartphone yaitu perintah untuk menggerakan robot, perintah untuk menggerakan servo kepala, dan perintah untuk berkomunikasi pada robot teman. Ketika perintah yang diterima mikrokontroler ATmega324 berupa perintah motion, maka mikrokontroler akan mengirimkan paket data sesuai dengan motion yang diinginkan ke pengendali motor servo RCB-4. Jika mikrokontroler ATmega324 menerima perintah untuk menggerakan servo kepala, maka nilai $O C R 1 A / B$ akan berubah sesuai dengan sudut yang diinginkan. Sedangkan jika perintah yang diterima mikrokontroler ATmega324 adalah perintah untuk berkomunikasi pada robot teman, maka mikrokontroler ATmega324 akan mengirimkan data ke mikrokontroler ATmega8 melalui pin $\mathrm{I} / \mathrm{O}$.

Pemroses data komunikasi menggunakan mikrokontroler ATmega8 yang bertugas mengirimkan data ke robot teman dan menerima data dari robot teman melalui bluetooth yang kemudian dikembalikan ke kontrol utama dengan menggunakan pin I/O.

\subsection{Algoritma - algoritma Perangkat Lunak Pengendali Robot}

Pada bagian ini akan dibahas algoritma - algoritma perangkat lunak pengendali ketika robot sedang bermain bola. Pembahasan akan diberikan dalam bentuk diagram alir secara keseluruhan dan diagram alir tiap prosedur agar dapat dipahami secara lebih detail. 


\subsubsection{Algoritma Keseluruhan}

Algoritma keseluruhan robot adalah algoritma yang berisi semua pergerakan robot ketika bermain di lapangan dalam merespons segala kondisi bola, gawang, posisi robot di lapangan, dan lainnya. Pada dasarnya prosedur pergerakan robot ketika bermain di lapangan adalah sebagai berikut:

1. Tracking bola : melihat bola dan menggerakan servo pan dan tilt robot sampai bola terlihat di tengah-tengah pandangan kamera.

2. Analisis posisi bola terhadap robot : menganalisis posisi bola berdasarkan sudut servo pan dan tilt robot setelah melakukan tracking bola.

3. Mendekati bola : melakukan gerakan berjalan maju dan putar ditempat untuk mendekati bola berdasarkan posisi bola terhadap robot.

4. Penentuan orientasi : membandingkan arah orientasi robot dengan arah orientasi menyerang (arah gawang lawan) dan mengubah arah orientasi jika tidak sesuai.

5. Penentuan posisi gawang : mencari gawang lawan dan menyearahkan arah orientasi robot untuk mengarahkan tendangan ke gawang lawan.

6. Penempatan diri menendang bola : memosisikan diri hingga bola berada tepat di depan kaki kanan atau kiri, sehingga robot dapat menendang bola dengan baik.

7. Tendang bola : melakukan gerakan menendang bola.

Sebagai tambahan, ada algoritma komunikasi antar robot sebagai sarana koordinasi. Siklus algoritma keseluruhan ini diilustrasikan pada Gambar 2.

\subsubsection{Algoritma Tracking dan Analisis Posisi Bola}

Pada bagian ini dilakukan juga dilakukan perbaikan penentuan perubahan sudut servo kepala ketika robot melakukan tracking bola dengan cara memperbaiki kontrol overshoot servo. Gambar 3 menunjukan diagram alir ketika robot melakukan tracking bola.

Perbaikan utama bagian ini adalah dalam hal menghitung selisih koordinat bola dengan daerah toleransi. Untuk lebih jelasnya berikut adalah gambar vision kamera robot dan daerah toleransi yang dimaksud. Resolusi gambar yang digunakan adalah 480x320 piksel. Sedangkan daerah toleransi adalah 30×20 piksel di tengah dan kotak bergaris tebal adalah batas daerah toleransi.

Bola dinyatakan terkunci atau sudah didapatkan ketika koordinat bola sudah berada di dalam daerah toleransi. Jika koordinat bola berada di luar batas toleransi, maka servo kepala robot akan bergerak sedemikian hingga koordinat bola dapat berada di dalam batas toleransi. Pergerakan servo tersebut dikendalikan dengan algoritma tracking bola. Pada algoritma ini, nilai perubahan sudut servo dihasilkan dengan memasukan selisih koordinat bola dengan daerah toleransi ke dalam sebuah persamaan regresi. Persamaan tersebut didapat dari melakukan sampling nilai-nilai perubahan sudut servo terhadap selisih koordinat bola dengan daerah toleransi yang kemudian dari data tersebut dibuat grafik. Persamaan garis dari grafik tersebut kemudian digunakan untuk menghitung perubahan sudut servo, seperti yang terlihat pada Gambar 5.

Sumbu $Y$ dengan label $d_{-}$Servo adalah nilai perubahan sudut servo dan sumbu $X$ dengan label $d \_K \_B o l a$ adalah selisih koordinat bola dengan daerah toleransi. Sedangkan persamaan tersebut adalah persamaan dari trendline grafik yang secara otomatis dibuat dari program Microsoft Excel. Persamaan tersebut dapat berubah-ubah sesuai dengan hasil sampling yang dilakukan. Sesuai dengan grafik tersebut, nilai perubahan sudut 
servo kepala dapat berubah-ubah dengan nilai lebih bervariasi, hasilnya servo dapat bergerak lebih halus dan cepat ketika merespon perpindahan bola.

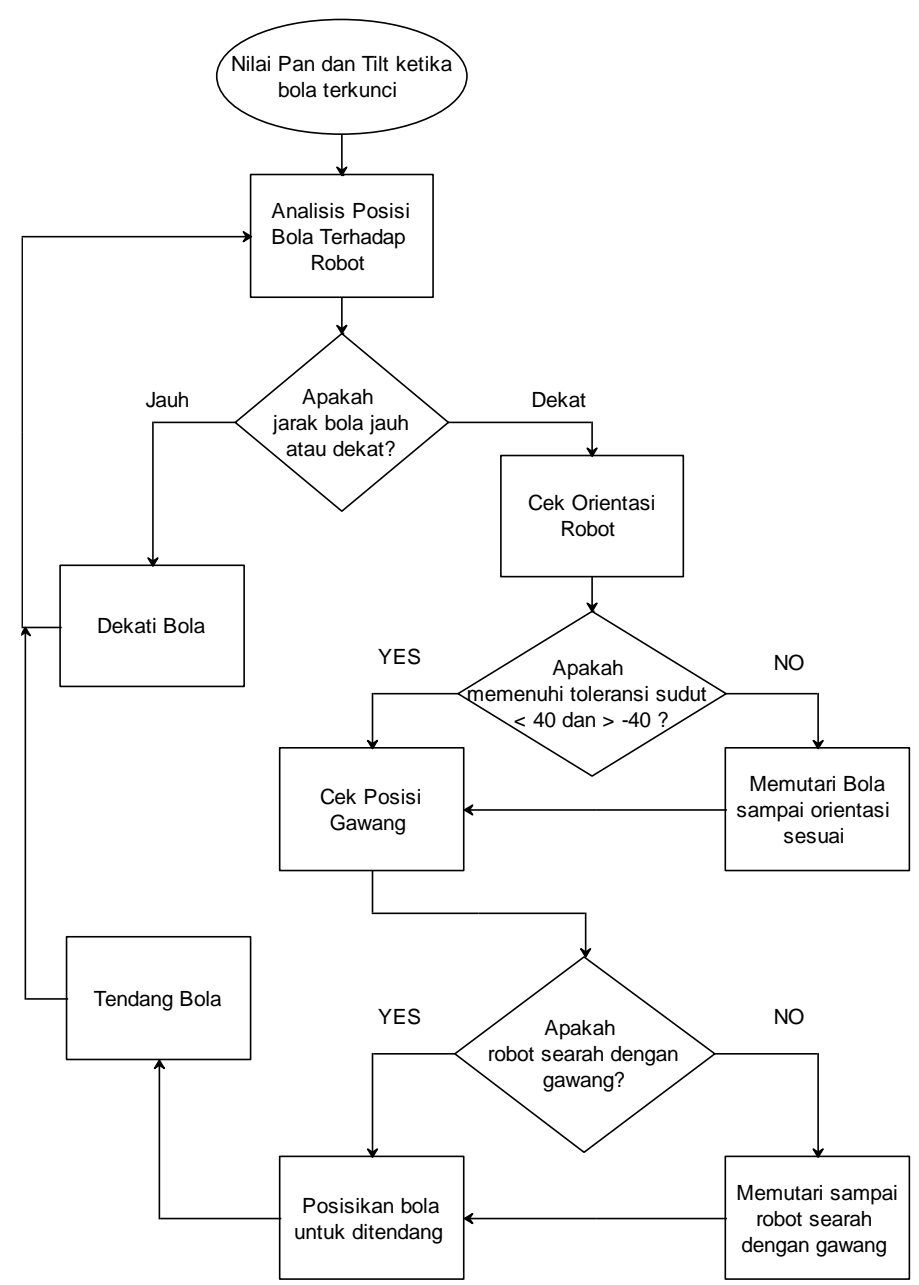

Gambar 2. Diagram alir algoritma keseluruhan

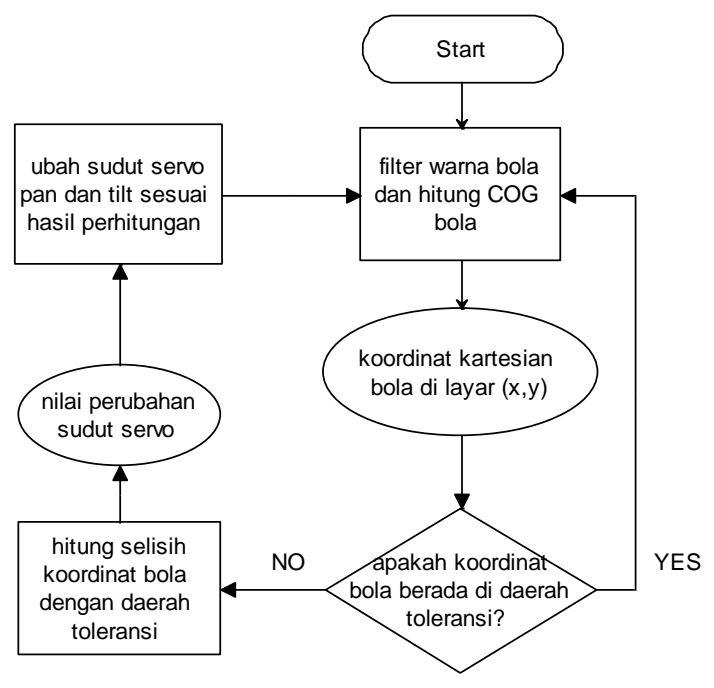

Gambar 3. Diagram alir algoritma tracking bola 


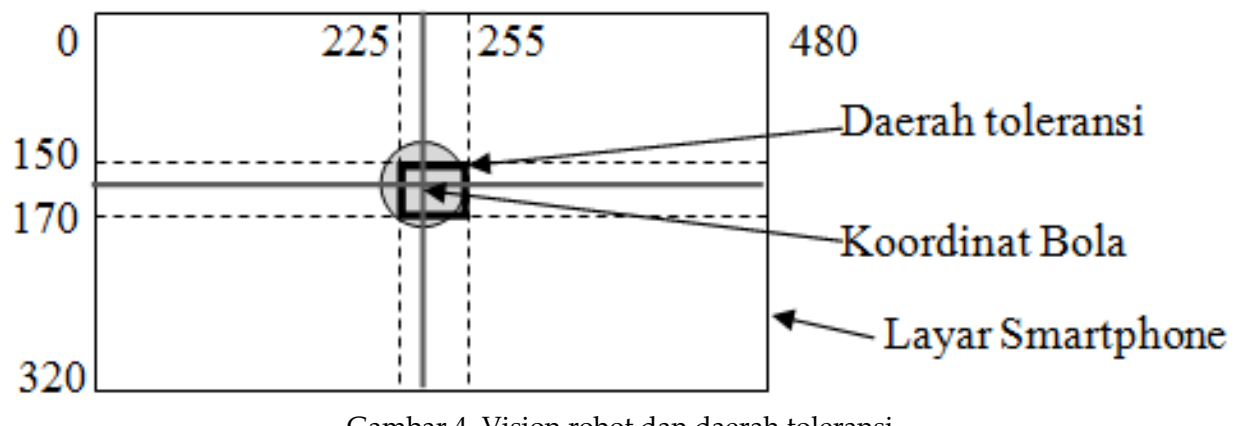

Gambar 4. Vision robot dan daerah toleransi

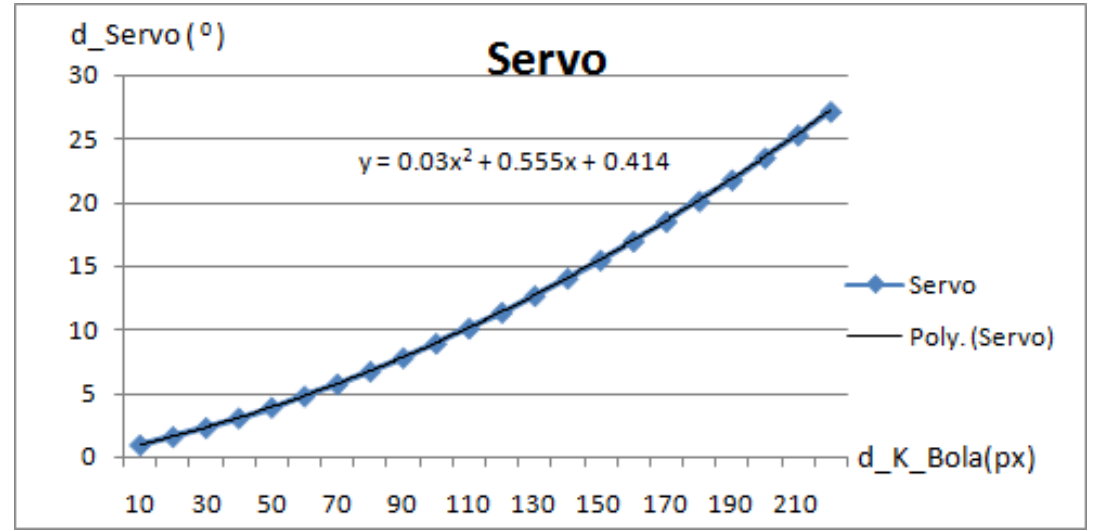

Gambar 5. Grafik selisih koordinat bola dengan batas toleransi terhadap perubahan sudut sero

Setelah proses tracking bola dilakukan, maka akan didapatkan nilai sudut pan dan tilt servo ketika robot sudah mendapatkan bola. Sudut pan dan tilt tersebut kemudian digunakan untuk memperkirakan posisi bola terhadap robot.

\subsubsection{Algoritma Mendekati Bola}

Optimalisasi kecepatan robot mendekati bola dilakukan dengan mengganti metode pemanggilan motion yang sebelumnya menggunakan counter menjadi tanpa menggunakan counter. Counter yang dimaksud adalah jumlah robot melakukan motion. Misalnya dikirimkan perintah melakukan motion jalan maju dengan counter sebanyak 3, maka robot akan melakukan motion jalan maju sebanyak 3 langkah. Robot dapat bergerak dengan motion lain setelah counter tersebut selesai dilakukan. Hal ini menyebabkan robot menjadi kurang responsif terhadap pergerakan bola. Tanpa menggunakan counter, robot dapat berganti ke motion yang relevan dengan perubahan posisi bola dengan lebih cepat. Gambar 6 menunjukkan diagram alir algoritma mendekati bola tanpa counter.

\subsubsection{Algoritma Penentuan Orientasi Robot}

Penentuan orientasi robot perlu dilakukan untuk mengetahui posisi robot apakah cenderung menghadap gawang sendiri atau cenderung menghadap gawang lawan. Pada proses robot melakukan penentuan orientasi, sudut toleransi diperkecil menjadi $\pm 40^{\circ}$ terhadap garis tegak lurus lapangan supaya kemungkinan robot dapat menangkap lokasi gawang di segala posisi menjadi lebih besar. Karena simpangan maksimal servo pan kepala robot adalah $\pm 80^{\circ}$ maka diharapkan robot dapat melihat gawang dari posisi pinggir lapangan sekalipun. Kemungkinan robot tidak mendapatkan gawang dan 
menendang ke arah yang tidak seharusnya juga dapat diperkecil. Gambar 7 menunjukkan algoritma penentuan orientasi robot.

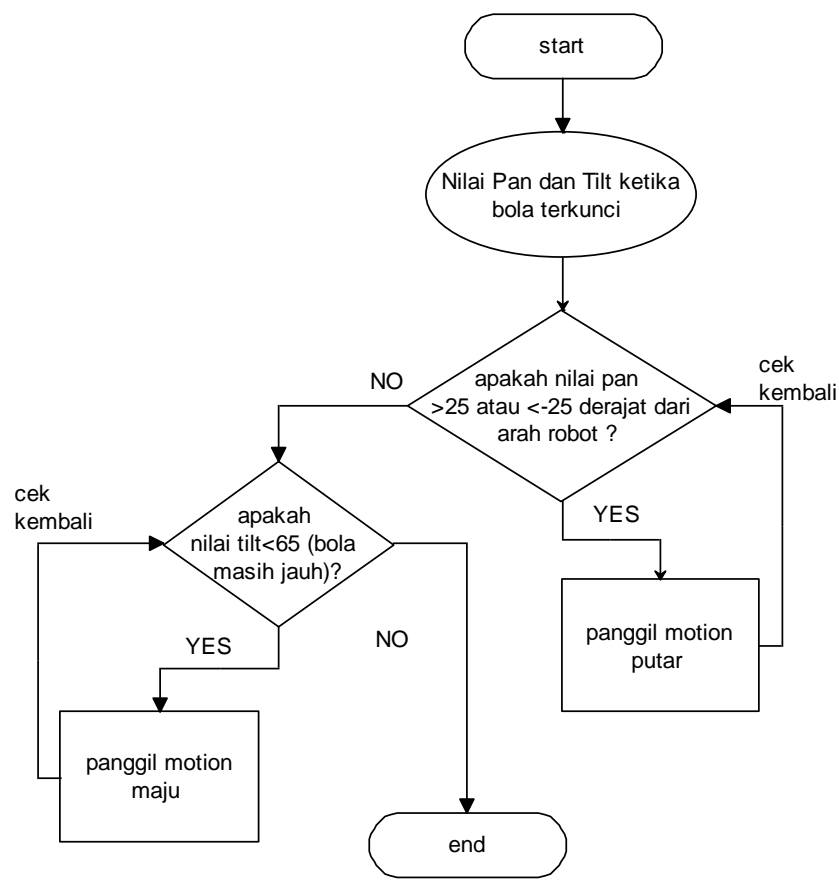

Gambar 6. Diagram alir algoritma mendekati bola

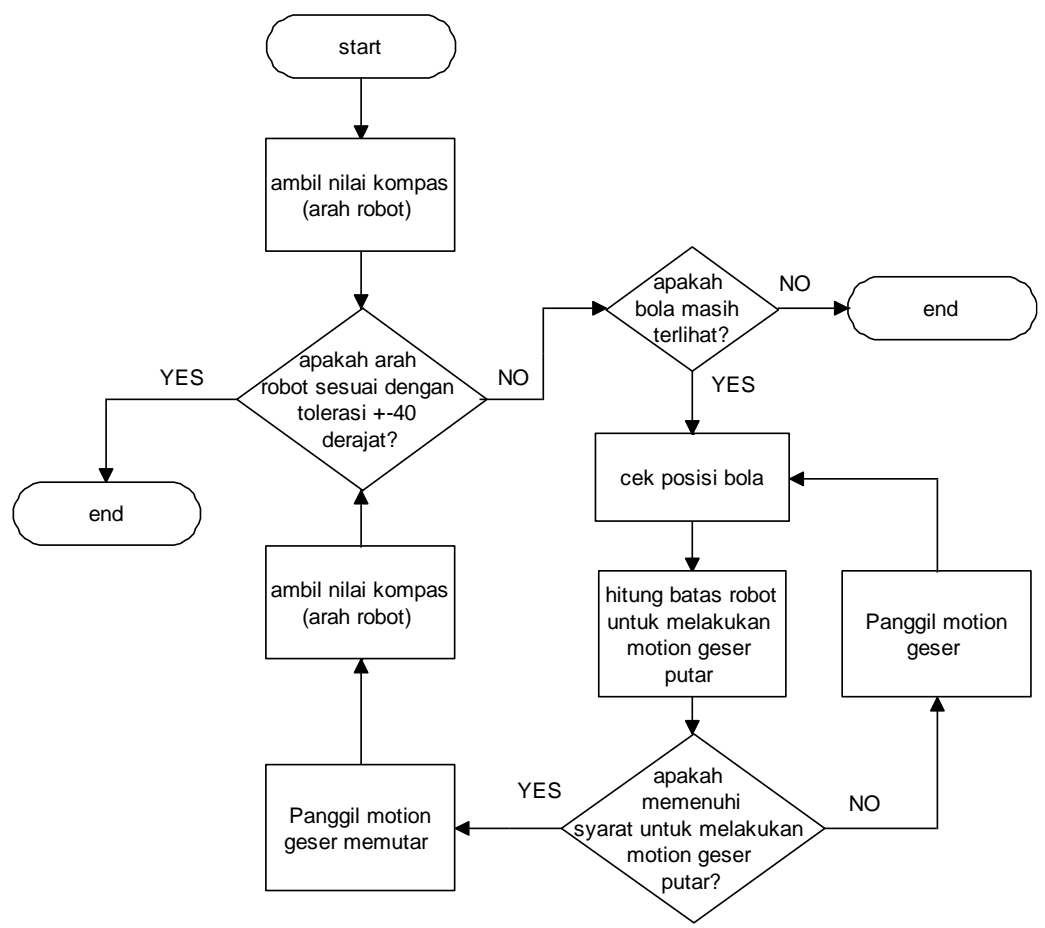

Gambar 7. Diagram alir algoritma penentuan orientasi robot 


\subsubsection{Algoritma Penentuan Posisi Gawang}

Algoritma ini digunakan untuk memutuskan posisi gawang apakah berada di depan, kanan, atau kiri robot. Untuk itu robot hanya perlu melihat ke depan, kanan atau kiri tanpa melakukan tracking gawang.

Dengan menggunakan algoritma ini, pergerakan robot diubah menjadi tidak memutari bola namun hanya berputar ditempat sehingga waktu yang dibutuhkan lebih cepat. Selain itu algoritma ini tidak menggunakan kompas untuk acuan arah gawang, namun menggunakan kamera yang melihat gawang secara realtime sehingga lebih akurat dan dapat diandalkan. Gambar 8 menunjukkan diagram alirnya.

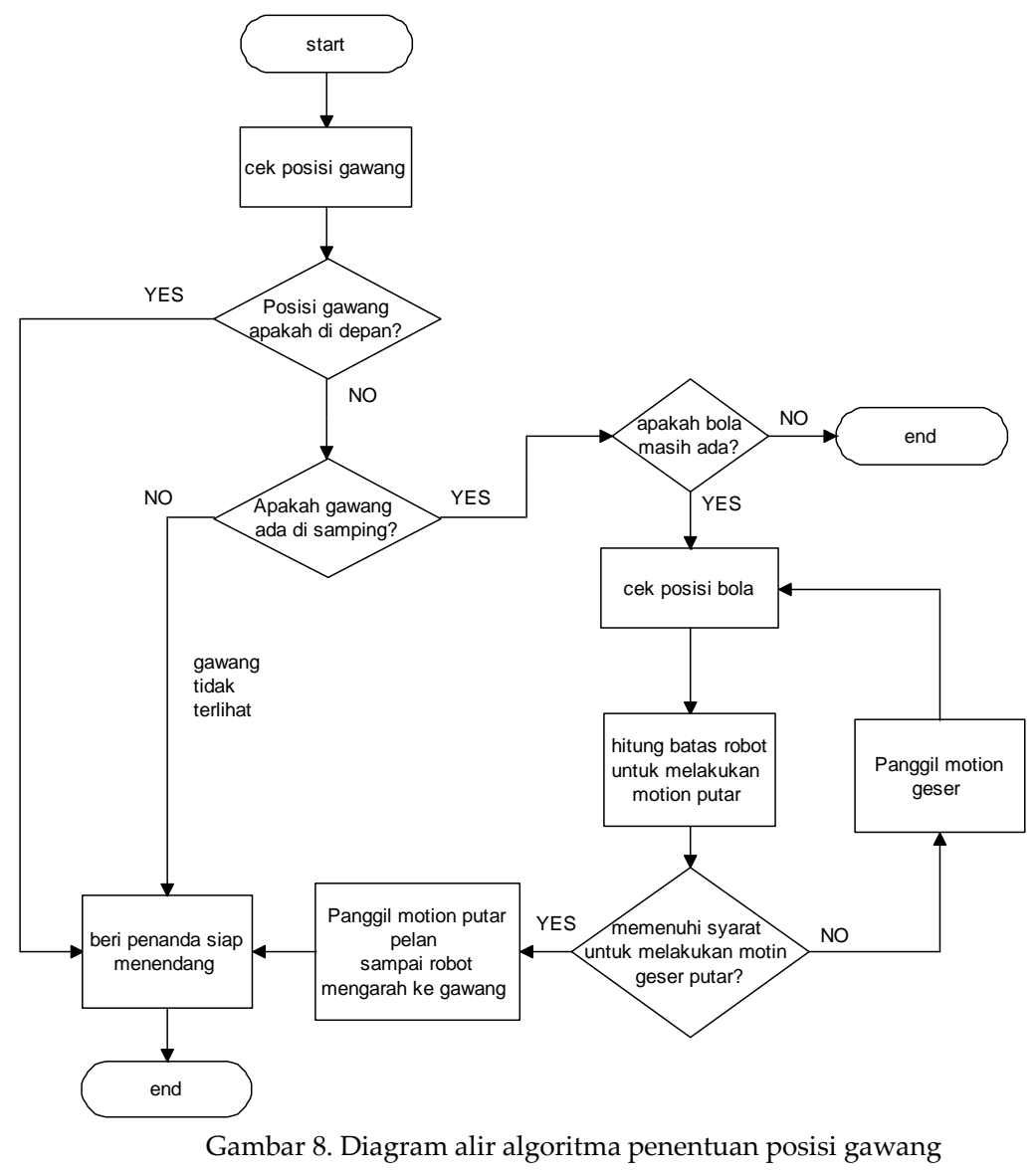

\subsubsection{Algoritma Menempatkan Diri Menendang Bola}

Algoritma ini menggunakan bantuan rute pergerakan robot yang sesuai dengan kaki kanan dan kaki kiri robot. Rute ini di buat dengan melakukan sampling posisi robot terhadap bola yang di representasikan dalam besaran sudut servo pan dan tilt kepala robot. Dengan bantuan rute ini, diharapkan robot dapat bergerak memosisikan diri menendang bola dengan lebih akurat dan mampu melakukan tendangan menggunakan kaki kanan maupun kaki kiri. Rute pergerakan, robot dan posisi bola dapat diilustrasikan pada Gambar 9. 


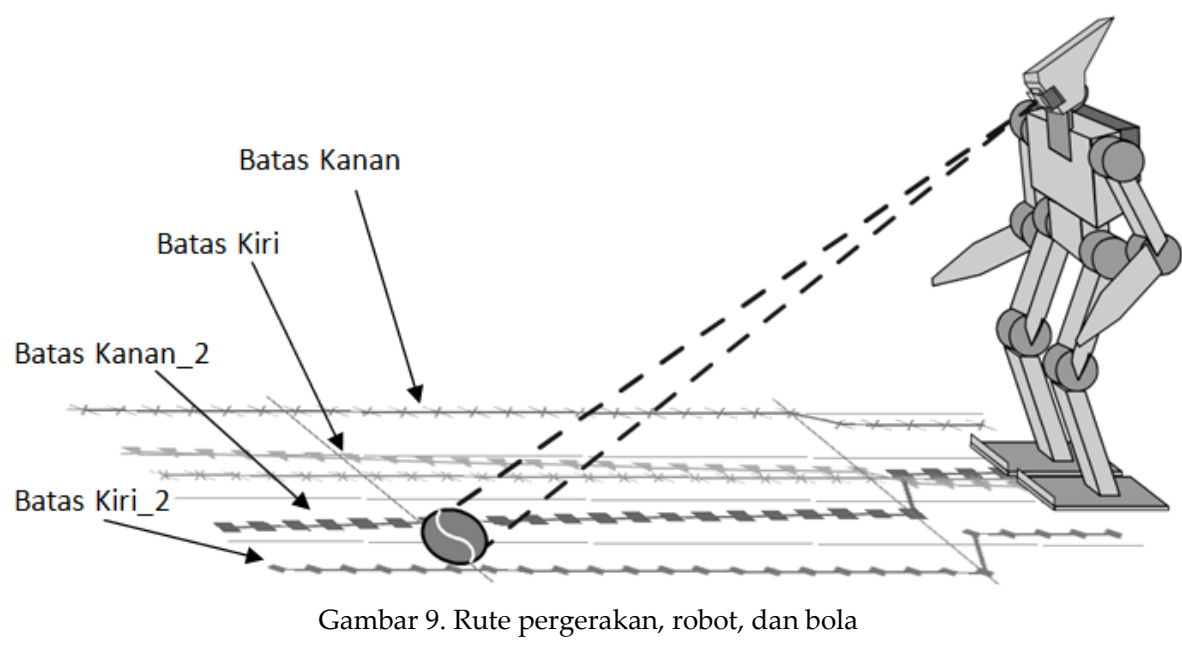

Ketika bola cenderung berada di sebelah kiri robot, maka robot akan menggunakan batas kanan_2 dan batas kiri_2 sebagai rute pergerakan robot. Sebaliknya, jika bola cenderung berada di sebelah kanan robot, maka akan digunakan batas kanan dan batas kiri sebagai rute pergerakannya.

\subsubsection{Algoritma Menendang Bola}

Sebelum robot melakukan shooting, dipastikan robot telah melakukan proses penentuan orientasi robot dan penentuan posisi gawang sehingga kemungkinan robot menendang ke arah yang tidak seharusnya dapat diminimalkan. Gambar 10 menunjukkan diagram alir algoritma menendang bola.

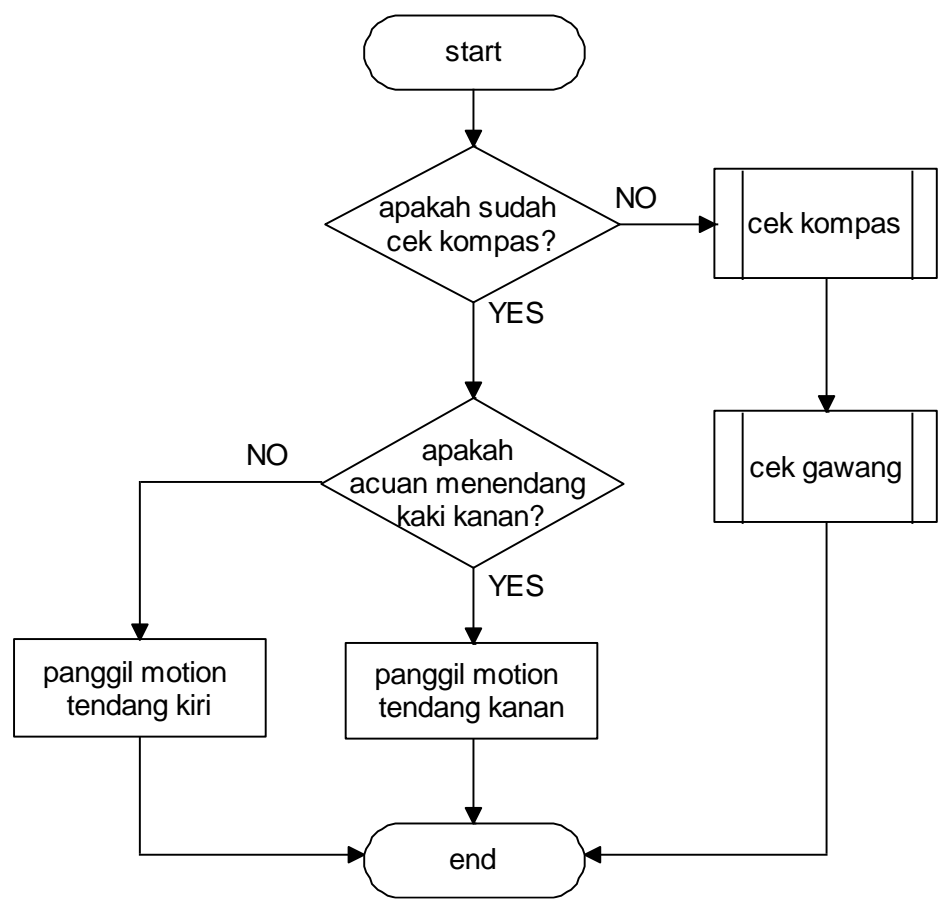

Gambar 10. Diagram alir algoritma menendang bola 


\subsubsection{Algoritma Komunikasi Robot}

Untuk komunikasi antar robot, digunakan bluetooth sebagai media komunikasi data nirkabel. Bluetooth ini memiliki antarmuka serial UART yang sudah berlevel tegangan TTL sehingga dapat langsung digunakan dengan mikrokontroler ATmega8. Algoritma komunikasi robot ini sederhana, ketika satu robot sudah dekat dengan bola maka robot itu akan menginstruksikan robot lain untuk berhenti sampai robot yang memegang bola menginstruksikan untuk kembali bergerak. Berikut adalah diagram alir algoritma komunikasi antar robot.

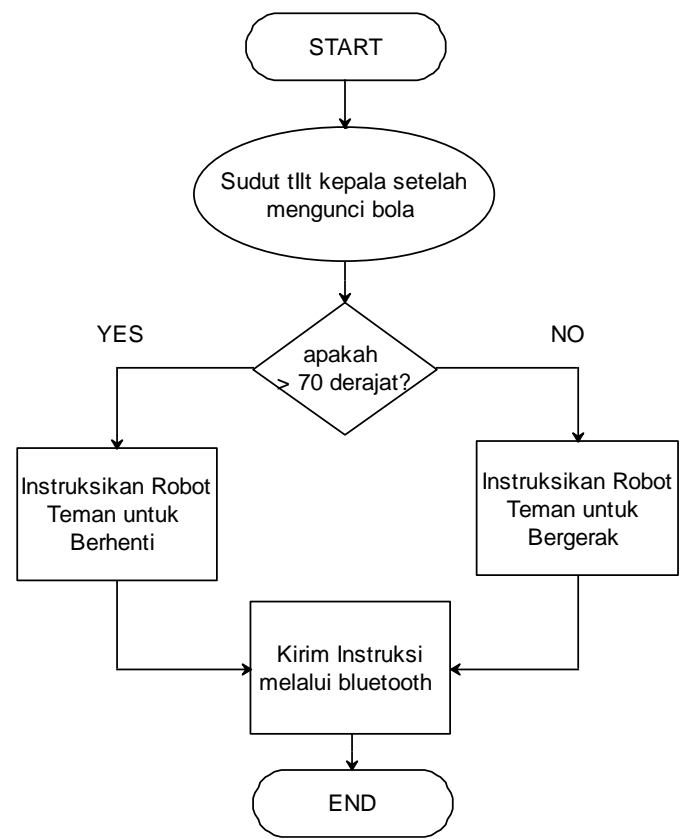

Gambar 11. Diagram alir algoritma komunikasi

\section{Pengujian dan Pembahasan}

Pada bagian ini akan dipaparkan mengenai pengujian algoritma yang diterapkan dan analisis hasil pengujiannya. Tujuan pengujian ini untuk mengetahui kinerja algoritma yang telah dikembangkan dan tingkat keberhasilan spesifikasi yang diusulkan.

\subsection{Pengujian Overshoot Servo Kepala}

Pengujian dilakukan dengan menggelindingkan bola dengan kecepatan kira - kira 20 $\mathrm{cm}$ per detik dari beberapa jarak (s) berbeda dari robot. Gambar 12 menunjukkan ilustrasi pengujian overshoot servo.

Overshoot diukur dengan menghitung waktu kepala robot bergerak setelah bola berhenti (semakin cepat waktu berhenti maka sistem semakin baik). Tabel 1 menunjukkan hasil pengujuan overshoot servo kepala robot pada berbagai jarak bola dari robot. 


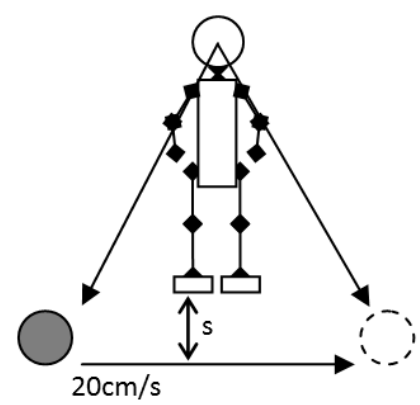

Gambar 12. Ilustrasi pengujian overshoot servo kepala

Tabel 1. Pengujian overshoot servo kepala

\begin{tabular}{|c|c|}
\hline Posisi bola terhadap robot $(\mathrm{cm})$ & Lama overshoot (ms) \\
\hline 10 & 810 \\
\hline 30 & 670 \\
\hline 60 & 480 \\
\hline 100 & 400 \\
\hline 200 & 250 \\
\hline
\end{tabular}

Pada tabel tersebut dapat dilihat bahwa waktu overshoot semakin besar apabila jarak bola dengan robot semakin dekat. Meskipun demikian waktu overshoot terlama dalam pengujian ini tetap di bawah 1 detik. Sebelum dilakukan optimalisasi, overshoot terlama 1,4 detik.

\subsection{Pengujian Keberhasilan Robot Memutari Bola}

Pengujian dilakukan dengan menjalankan robot berlawanan arah $180^{\circ}$ dengan arah gawang lawan, kemudian memutari bola sampai sudut toleransi sesuai. Keberhasilan diukur dengan mengamati apakah robot menyampar bola atau tidak. Berikut ini adalah ilustrasi dari pengujian yang dilakukan.

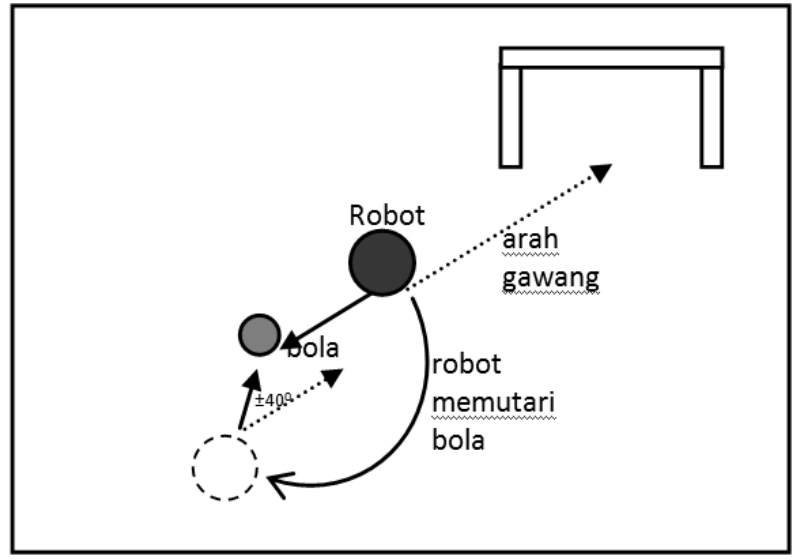

Gambar 13. Ilustrasi pengujian robot memutari bola

Dari 10 kali percobaan didapatkan persentase kesesuaian robot arah terhadap gawang sebesar $100 \%$ dan persentase robot tidak menyampar bola sebesar $80 \%$. Saat robot menyampar bola disebabkan oleh motion cut sehingga kaki robot terpeleset dan menyampar bola. Sebelum dilakukan optimalisasi persentase kesesuaian arah sebesar $90 \%$ dan persentase tidak menyampar bola sebesar $70 \%$. 


\subsection{Pengujian Respon Robot terhadap Perpindahan Bola}

Pengujian dilakukan dengan menggeser bola sejauh kira - kira $30 \mathrm{~cm}$ ke samping ketika robot bergerak dalam berbagai macam kondisi pergerakan. Respon robot diukur dengan mulai dari bola selesai dipindahkan sampai robot berhenti melakukan motion sebelumnya dan mengikuti perpindahan bola dengan melakukan motion yang sesuai. Gambar 14 menunjukkan ilustrasi pengujian.

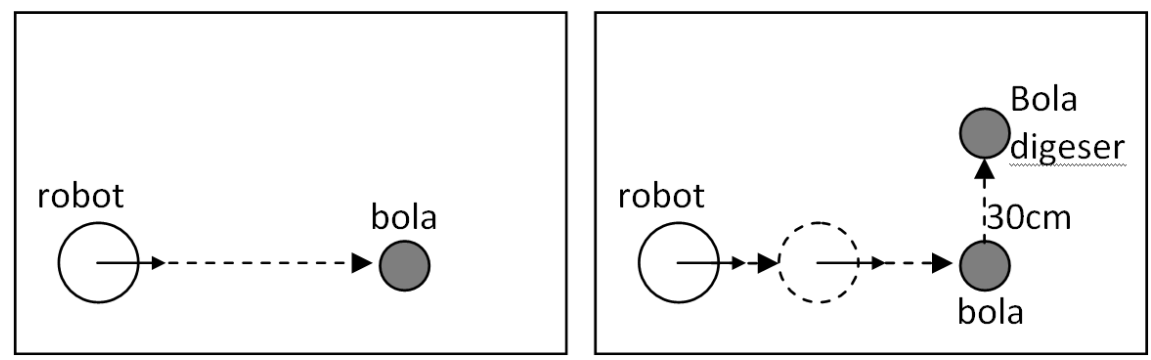

Gambar 14. Ilustrasi pengujian respon robot terhadap perpindahan bola

Dari 10 kali pengujian didapatkan waktu respon bervariasi antara $320 \mathrm{~ms}-630 \mathrm{~ms}$ dengan rata - rata $417 \mathrm{~ms}$. Berarti robot rata - rata dapat merespon perpindahan bola dalam waktu kurang dari setengah detik.

\subsection{Pengujian Kemampuan Robot Mengarahkan Bola ke Gawang}

Pengujian dilakukan dengan memosisikan bola pada daerah samping gawang supaya robot harus mencari posisi gawang dan mengarahkan diri ke gawang. Robot kemudian dijalankan dengan posisi membelakangi gawang sehingga robot harus memutar menyesuaikan kompas terlebih dahulu baru kemudian bersiap untuk mengarahkan diri ke gawang. Waktu diukur dari robot memulai melihat gawang sampai robot melakukan tendangan dan posisi bola berjarak antara 5 - $10 \mathrm{~cm}$ dari robot. Gawang yang digunakan berupa objek warna kuning dengan lebar 1.5 meter. Gambar 15 menunjukkan ilustrasi pengujian.
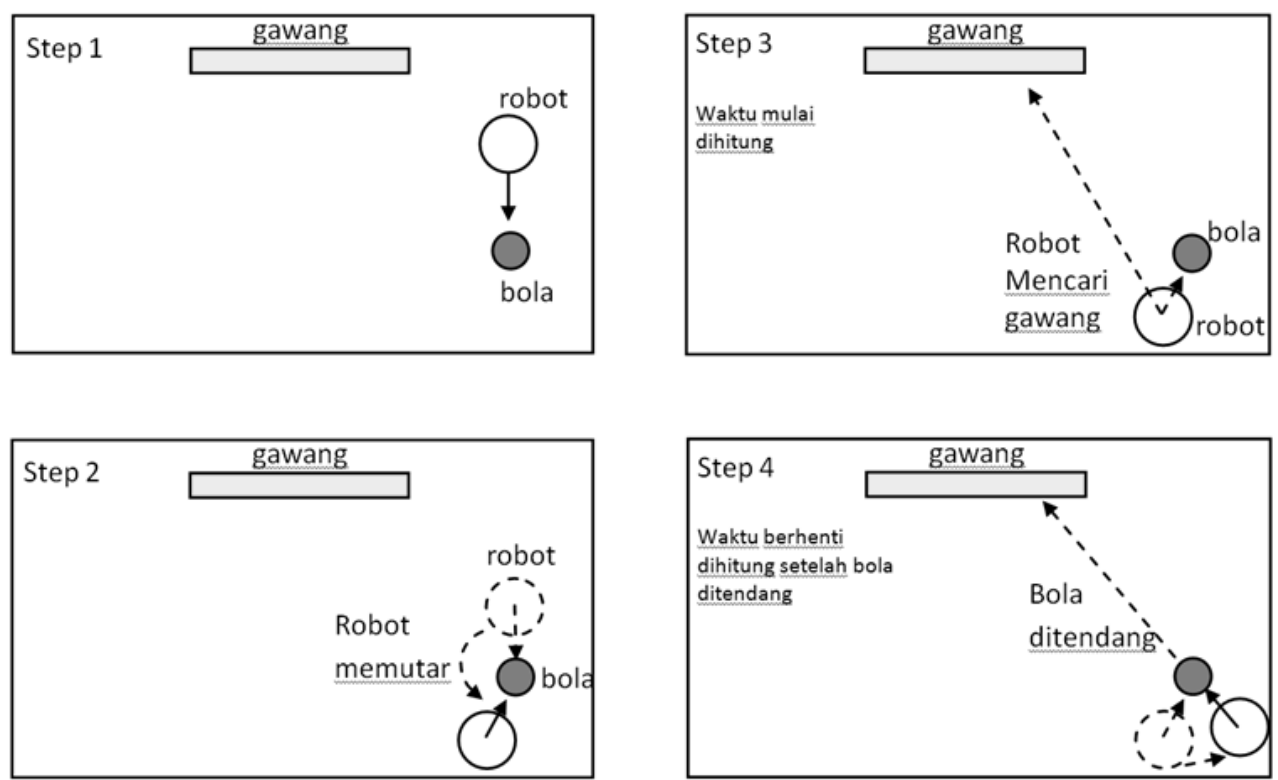

Gambar 15. Ilustrasi pengujian robot mengarahkan bola ke gawang 
Dari 10 kali percobaan, rata - rata robot membutuhkan waktu 11 detik untuk melakukan tendangan sejak gawang terlihat dalam jangkauan. Persentase keberhasilan dalam mencetak gol mencapai $90 \%$. Sebelum dilakukan optimalisasi, rata - rata robot membutuhkan waktu 27 detik untuk proses yang sama dan persentase keberhasilan mencatak gol hanya $60 \%$.

\subsection{Pengujian Sistem Komunikasi Robot}

Pengujian pertama adalah pengujian proses pengiriman data yang dilakukan dengan memberi LED pada board komunikasi sebagai penanda dan kemudian robot dimainkan. Keberhasilan diukur dengan nyala LED ketika robot sudah mendapat bola dan mematikan LED kembali setelah posisi bola jauh atau bola sudah ditendang.

Pengujian kedua adalah pengujian sistem keseluruhan yang dilakukan dengan 2 robot yang dijalankan bersamaan. Keberhasilan diukur dengan berhentinya salah satu robot ketika robot yang lain sudah mendapat bola dan robot dapat kembali bergerak tanpa kesalahan pemanggilan motion setelah bola sudah ditendang atau sudah tidak dikuasai oleh robot.

Kedua pengujian di atas berhasil dengan sempurna. Robot yang tidak mendapat bola selalu dapat berhenti untuk memberi kesempatan robot yang mendapat bola untuk melakukan manuver untuk mencetak gol.

\section{Kesimpulan}

Berdasarkan perancangan, perealisasian dan pengujian dapat ditarik kesimpulan sebagai berikut :

1. Proses pemanggilan motion tanpa menggunakan counter dapat lebih responsif dalam menanggapi perpindahan bola.

2. Penggunaan sudut pan dan tilt dalam menentukan batasan-batasan robot melakukan motion memutari bola dapat memperkecil kemungkinan tersamparnya bola oleh kaki robot.

3. Optimalisasi algoritma - algoritma yang berkaitan dengan eksekusi tendangan telah dapat meningkatkan kecepatan dan kemungkinan robot dalam mencetak gol.

4. Fitur komunikasi antar - robot efektif dalam mencegah terjadinya rebutan bola.

\section{Daftar Pustaka}

[1] P. Nasrollahi, S. Jafari, M. Bazmara, and A. Nikooee, "Player level decision making of humanoid soccer robots using fuzzy rule - based classification system," Journal of Basic and Applied Scientific Research, vol. 3, no. 11, hal. 439 - 446, 2013.

[2] R.D. Airlangga, S. Nugroho, and B.W. Yohanes, “Optimizing ball detection algorithm using center of gravity method and servo pan and tilt controller for humanoid soccer robotic based on Android," In Proc Engineering International Converence UNNES Conservation, hal. 142 - 146, 2013. 
